\title{
Stabilization of luteinizing hormone-releasing hormone in a dry powder formulation and its bioactivity
}

\author{
Titpawan Nakphenga ${ }^{\mathrm{a}}$, Somchai Sawatdee ${ }^{\mathrm{b}}$, Khemmarat Buaking ${ }^{\mathrm{b}}$, Teerapol Srichana $\mathrm{a}^{\mathrm{a}, \mathrm{b}}$ \\ ${ }^{a}$ Drug Delivery System Excellence Center; ${ }^{b}$ Department of Pharmaceutical Technology, Faculty of \\ Pharmaceutical Sciences, Prince of Songkla University, Hat Yai, Songkhla 90110, Thailand
}

\begin{abstract}
Background: Luteinizing hormone-releasing hormone (LHRH) is a naturally occurring hormone that controls sex hormones in both men and women. In general, LHRH is poorly absorbed through the gastrointestinal tract due to its large molecular size, high polarity, and loss from enzymatic degradation.

Objective: Prepare and develop LHRH in a dry power formulation with stability and biological activity.

Methods: Mannitol (M) and glycine (G) were chosen as ingredients to stabilize and protect LHRH during the freeze drying processes and during storage. The physicochemical properties of LHRH dry powders were examined by capillary electrophoresis, fluorescence spectrophotometry, scanning electron microscopy, and photon correlation spectroscopy. The release of LHRH from the dry powder was carried out in dissolution apparatus. In addition, a rat model was employed to study the bioactivity of LHRH in the dry powder form.

Results: The LHRH dry powder formulations using M and $\mathrm{G}$ in the ratios of 6:4 and 7:3 were more stable than other formulations. LHRH colloids containing $\mathrm{M}: \mathrm{G}$ showed no aggregation after storage at $4^{\circ} \mathrm{C}$ for one month. The concentration of LHRH in the dry powder form was more stable than that of LHRH in solution form. All the LHRH dry powder formulations were instantly dissolved within 10 seconds in an aqueous medium. After the LHRH dry powder $(13 \mathrm{mg})$ was reconstituted and administered intraperitoneally to male rats during a one-month period, the testosterone level in the plasma was significantly decreased compared with an untreated group $(15.0 \pm 1.0 \mathrm{ng} / \mathrm{mL}$, $15.0 \pm 1.0 \mathrm{ng} / \mathrm{mL}$ and $20.0 \pm 2.0 \mathrm{ng} / \mathrm{mL}$ for $\mathrm{LHRH}$ containing M:G; 6:4, 7:3, and 8:2, respectively, compared to the control of $35 \pm 2 \mathrm{ng} / \mathrm{mL}, \mathrm{p}<0.05)$.
\end{abstract}

Conclusion: The LHRH dry powder formulations had good physicochemical properties and bioactivity.

Keywords: Bioactivity, dry powder, luteinizing hormone-releasing hormone (LHRH), testosterone level

Luteinizing hormone-releasing hormone (LHRH) is a decapeptide containing pGlu-His-Trp-Ser-TyrGly-Leu-Arg-Pro-Gly-NH $\mathrm{NH}_{2}$ [1]. Its isoforms have been found in both vertebrate and invertebrate species [1-4]. LHRH binds to receptors in the pituitary gland, stimulating the release of luteinizing hormone (LH) and follicle stimulating hormone (FSH). LH and FSH stimulate the gonads to synthesize steroid hormones. Many analogs of LHRH are known including peptides related to LHRH that act as agonists and some that act as antagonists [5].

LHRH and LHRH analogs are known to be useful for treating hormone-dependent diseases such as

Correspondence to: Teerapol Srichana, $\mathrm{PhD}$, Department of Pharmaceutical Technology, Faculty of Pharmaceutical Sciences, Prince of Songkla University, Hat Yai, Songkhla 90110, Thailand. E-mail: teerapol.s@psu.ac.th prostate cancer, benign prostatomegaly, endometriosis, hysteromyoma, metrofibroma, precocious puberty, or breast cancer [6-9]. Administration by sustained release is preferred for both LHRH-related compounds and LHRH antagonists, as repeated administration can reduce the number of available receptors [10].

Currently, marketed formulations of LHRH, its analogs, and related compounds used for parenteral injection, are in aqueous solutions. LHRH is more unstable with poor solubility in aqueous solutions. Thus, there is a need to develop stabilized LHRH formulations.

One of the most common procedures to stabilize a protein is to convert it into a solid state by freezedrying or spray drying [11]. Although this method produces reasonably stable products, it can have deleterious effects on the protein structure and a 
chance of a loss of protein activity upon rehydration $[12,13]$. Stabilizing solutes can be added to labile proteins to protect them during preparation and storage [14]. A variety of solutes, including sugars and amino acids, are effective at minimizing protein denaturation when stress is imposed by dissolving them in aqueous systems [15-17]. These solutes have the capacity to protect even extremely unstable proteins such as phosphofructokinase and lactate dehydrogenase during the drying process $[18,19]$. When the protein is incorporated in a matrix consisting of amorphous stabilizers in its glassy state [14], stabilization is achieved because the mobility of the protein is strongly reduced [11, 20-23]. Identifying the appropriate protein to stabilizer ratio may be an additional strategy to improve the stability of a dried protein formulation [24].

Systemic delivery of macromolecules by inhalation has attracted considerable attention since many peptides or proteins are more efficiently absorbed from the lungs than from the oral, nasal, or transdermal routes $[25,26]$. This efficient systemic absorption results from the unique physiological features of the lung. These are its large absorptive surface area, the very thin diffusion path to the blood stream, the elevated blood flow, the relatively low metabolic activity locally, and the avoidance of a first-pass hepatic metabolism. Dry powder inhalers present longer stability over nebulizers and metered-dose inhalers for the delivery of peptide and protein therapeutics to the lung.

In this study, we determined the effects of various ratios of carrier (mannitol and glycine) on the stability of LHRH during storage. The drug deposition in vitro was evaluated in lung delivery efficiency of LHRH dry powder. An in vitro release of LHRH powder was tested using a dissolution apparatus. For the bioactivity studies of LHRH, an in vivo rat model was used, and their plasma testosterone levels were determined.

\section{Materials and Methods}

\section{Formulations of LHRH dry powder}

LHRH $(2.5 \mathrm{mg})$ and carriers $(650 \mathrm{mg})$ were dissolved in purified water $(6.5 \mathrm{~mL})$. The carriers are mannitol (M) and glycine (G) (Merck, Darmstadt, Germany). The ratios of M:G were 6:4, 7:3, and 8:2 $w / w$ at $10 \% w / v$ in aqueous solution. The mixture of each formulation was sprayed through spray gun with nozzle diameter of $1.0 \mathrm{~mm}$ (Walther Pilot,Wuppertal, Germany) at a flow rate of $1 \mathrm{~mL} / \mathrm{min}$ and atomizing pressure of 3.5 bars into a $-40^{\circ} \mathrm{C}$ acetone bath $(200 \mathrm{~mL})$ of freeze dryer (Eyela, Tokyo, Japan). The solid particles were obtained as suspended particles in liquid acetone and filtered through a $0.45 \mu \mathrm{m}$ polyamide membrane filter (Sartorius AG, Gottingen, Germany). The dry powder obtained on the filter was placed in a vacuum oven (Precision Scientific, Chicago, USA) for further drying at $30^{\circ} \mathrm{C}$ for 12 hours. The spray-dried mixture was sieved through a 20 micro $\mathrm{m}$ and used as a powder formulation. Each dose contains $13 \mathrm{mg}$ of mixture with about $50 \mu \mathrm{g}$ of LHRH. The spray-dried samples were transferred into tightly closed glass bottles and placed in a desiccator containing silica gel kept in a refrigerator at $4^{\circ} \mathrm{C}$ until used.

\section{Characterization of particle morphology}

The particle size and morphology of LHRH formulations were achieved using a scanning electron microscope (Joel LTD, Tokyo, Japan). A small amount of each sample was scattered onto an aluminum stub holding a clear double-sided adhesive tape. Then, the particles were coated with a 15 to $20 \mathrm{~nm}$ layer of gold using a sputter coater in an argon atmosphere (50 Pa) at $50 \mathrm{~mA}$ for 30 seconds. All micrographs were taken at an acceleration of $15 \mathrm{keV}$.

\section{Quantitative study of LHRH by capillary electrophoresis}

Capillary electrophoresis (CE) was carried out using a Bio-Rad BioFocus 3000 CE System with a polyacrylamide-coated capillary $(50 \mu \mathrm{m}$ id, $360 \mathrm{~mm}$ OD) $19.5 \mathrm{~cm}$. The capillary was rinsed with distilled water for 120 seconds following by phosphate buffer pH 2.5 (No. 148-5010, Bio-Rad, Ontario, CA, USA) diluted with water at a ratio of 1:9 for 180 seconds, prior to each sample injection. Samples were loaded by applying a nitrogen pressure and the voltage across the capillary was set at $10 \mathrm{kV}$. The temperature of the capillary and sample was maintained at $20^{\circ} \mathrm{C}$ by a liquid cooling system. LHRH dry powder formulations $(13 \mathrm{mg})$ were dissolved in $1 \mathrm{~mL}$ of diluted phosphate buffer $\mathrm{pH} 2.5$ to give a final concentration of $50 \mu \mathrm{g} /$ $\mathrm{mL}$. The contents of LHRH were analyzed by CE and repeated at one and two months after storage at room temperature. 


\section{Drug dissolution studies}

The drug release studies were performed using a modified dissolution apparatus II (Hansen Research, Chatsworth, USA). LHRH dry powder formulation $(13 \mathrm{mg})$ consisted of LHRH $50 \mu \mathrm{g}$ was loaded into dissolution medium containing $10 \mathrm{~mL}$ of diluted phosphate buffer $\mathrm{pH} 2.5$ (1:9). The paddle was rotated at $100 \mathrm{rpm}$, and the temperature was maintained at $37^{\circ} \mathrm{C}$. At appropriate time intervals, $500 \mu \mathrm{L}$ aliquots of the receptor medium were withdrawn and replaced with fresh dilute phosphate buffer. The samples were collected at $0,5,10,30,60$, and 120 seconds after loading the LHRH dry powder into the dissolution flask. A LHRH standard was diluted with a buffer to give a final LHRH concentration of $1,2,3,4$, and $5 \mu \mathrm{g} / \mathrm{mL}$. The amount of LHRH release into the dissolution medium was analyzed by the CE method as described previously, and calculated according to a standard curve.

\section{Aggregation of LHRH formulation}

The LHRH formulations were dissolved in water to give a final LHRH concentration of $2.5 \mu \mathrm{g} / \mathrm{mL}$. Aggregations of LHRH after reconstitution were evaluated by time-drive intensity with a Luminescence spectrometer LS 50B (Perkin Elmer, Washington DC, USA). The luminescence was obtained from the excitation and emission wavelengths of 445 and 450 $\mathrm{nm}$, respectively, and slits were set at $10 \mathrm{~mm}$. The samples were analyzed at $0,7,14,21,28$, and 35 days after storage.

\section{Particle size analysis of LHRH suspensions}

The LHRH formulations containing 10\% M:G carriers in a ratio of $8: 2,7: 3$, and $6: 4 \mathrm{w} / \mathrm{w}$ were dissolved in diluted phosphate buffer $\mathrm{pH} 2.5$ to give a final concentration of LHRH at $100 \mu \mathrm{g} / \mathrm{mL}$. The LHRH suspensions were examined using a photon correlation spectroscopy (PCS, Malvern instruments, Worcestershire, UK).Samples were collected every day for up to 20 days.

\section{In vitro deposition of LHRH dry powder formulation}

The in vitro deposition of the formulations was determined using a twin stage impinger (TSI) with modification by Srichana et al. [27]. Briefly, LHRH dry powder was aerosolized by drawing air through the TSI at a flow rate of $60 \mathrm{~L} / \mathrm{min}$ for 10 seconds. Drug deposition on each stage of impinger was determined by $\mathrm{CE}$ as described in the previous section. The amount of LHRH depositing on the upper and lower stage of TSI were expressed as a percentage of the nominal dose.

\section{Bioactivity study of LHRH dry powder on plasma testosterone level in male rat}

Male Wistar rats (body weight: approximately 200 g) were separated into four groups (six rats per group) for treatment with LHRH dry powder containing in ratios of $M: G, 6: 4,7: 3$, and 8:2 and a control group. The animals were housed in cages and allowed food and water ad libitum throughout the duration of this study.

The procedures of animals handling were in accordance with the guidance of Animal Ethics Committee of Prince of Songkla University. LHRH dry powders were dissolved with $0.9 \%$ sodium chloride to give a final concentration of LHRH of $50 \mu \mathrm{g} / \mathrm{mL}$. Rats were anesthetized by an intraperitoneal injection of sodium pentobarbital (Sigma, St Louis, USA) at a dose of $50 \mathrm{mg} / \mathrm{kg}$. LHRH solution $(1 \mathrm{~mL})$ to each animal and $1 \mathrm{~mL}$ of $0.9 \%$ sodium chloride were administered intraperitoneally to the control group.

Blood samples $(1 \mathrm{~mL})$ were taken from the retroorbital plexus prior to LHRH administration and at day 3, 7, 14, 21, and day 28 after administration. Blood samples were allowed to clot, and the plasma was separated by centrifugation at $10,000 \mathrm{rpm}$ for five minutes. Plasma was kept at $-20^{\circ} \mathrm{C}$ until used. The plasma testosterone concentration was determined by HPLC (Waters, Boston, MA, USA) using a UV detector at a wavelength $254 \mathrm{~nm}$. The mobile phase consisted of $\mathrm{MeOH}$ (Mallinckrodt Baker, Phillipsburg, USA) and $25 \mathrm{mM} \mathrm{K} \mathrm{HPO}_{4}$ (Carlo Erba Reagent, Milan, Italy) at the ratio of 7:3 $(\mathrm{v} / \mathrm{v})$. The stationary phase was a $\mathrm{C}_{18}$ column $(250 \mathrm{~mm}$ id, $5 \mu \mathrm{m}$, Phenomenex, California, USA). The flow rate was 1 $\mathrm{mL} / \mathrm{min}$ and the injection volume was $100 \mu \mathrm{L}$. Testosterone and clotrimazole (Sigma, St Louis, USA) were used as standard and internal standard, respectively. The results were calculated using the peak area ratio of testosterone and clotrimazole with a standard curve.

\section{Statistical analysis}

All results were expressed as means \pm SD. Statistical comparisons were tested using a Student's $t$-test, and the differences were accepted as significant at the level of $\mathrm{p}<0.05$. 


\section{Results}

The particle morphology of the LHRH formulations was analyzed by scanning electron microscope. All LHRH morphologies varied from irregular shapes to rod shapes, and some showed aggregated individual particles. Figure 1 shows electron micrographs of LHRH dry powder formulations. Interestingly, all particle sizes varied between 1-5 $\mu \mathrm{m}$. Generally, the particles for a dry powder to be used for inhalation should have a preferred size range of $1-5 \mu \mathrm{m}$ for effective delivery to the lung [28-30]. This is similar to that of micronized materials, as it can be seen that the particles tended to be cohesive and formed agglomerates. There were no readily distinguishable differences in the morphology of the different formulations.

Figure 2 shows the content of LHRH formulations by CE. We note that the percent contents of the LHRH dry powders of M:G 8:2 significantly decreased after storage for one and two months, respectively. However, the formulations containing 7:3 and 6:4 M:G showed no significant decreases. These results indicate that the LHRH dry powder at these two ratios was stable in their dry solid form.

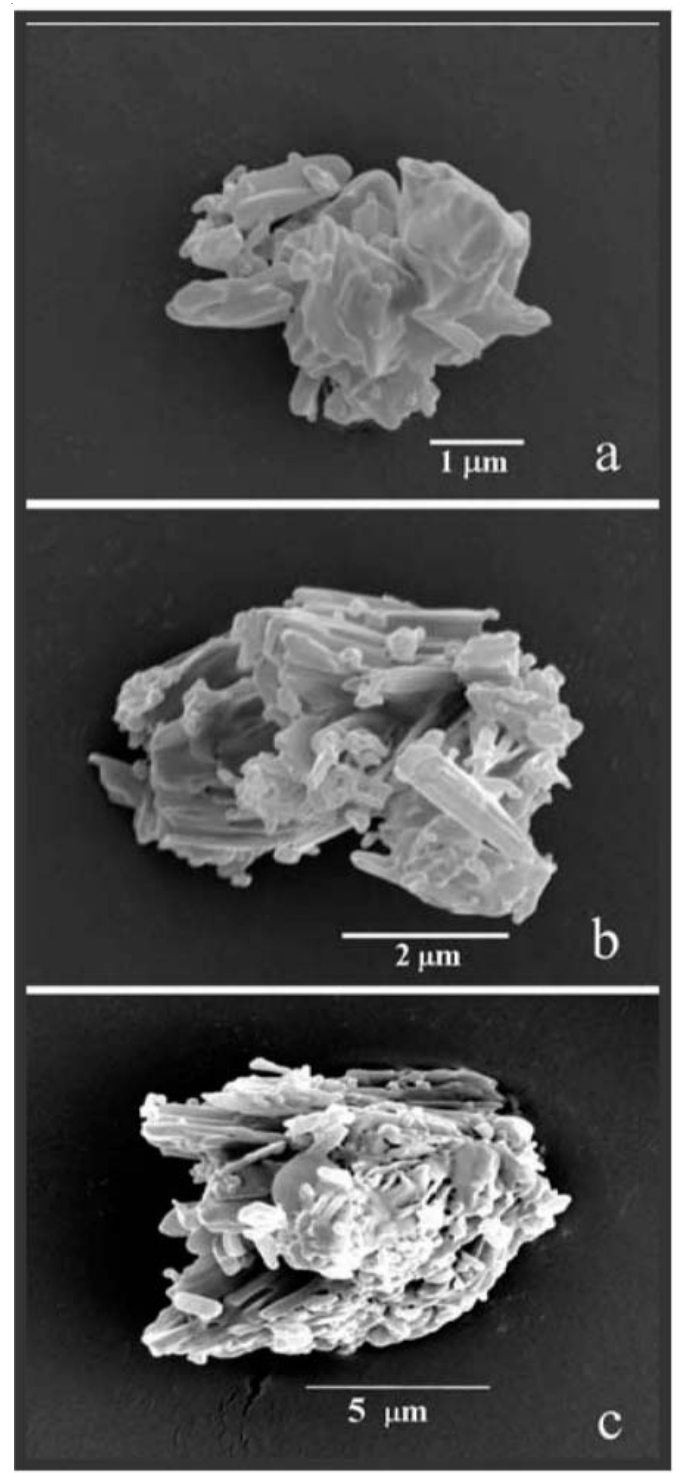

Figure 1. Electron micrographs of LHRH dry powder formulations: M:G, 6:4 formulation (a), M:G, 7:3 formulation (b) and M:G, 8:2 formulation (c). 


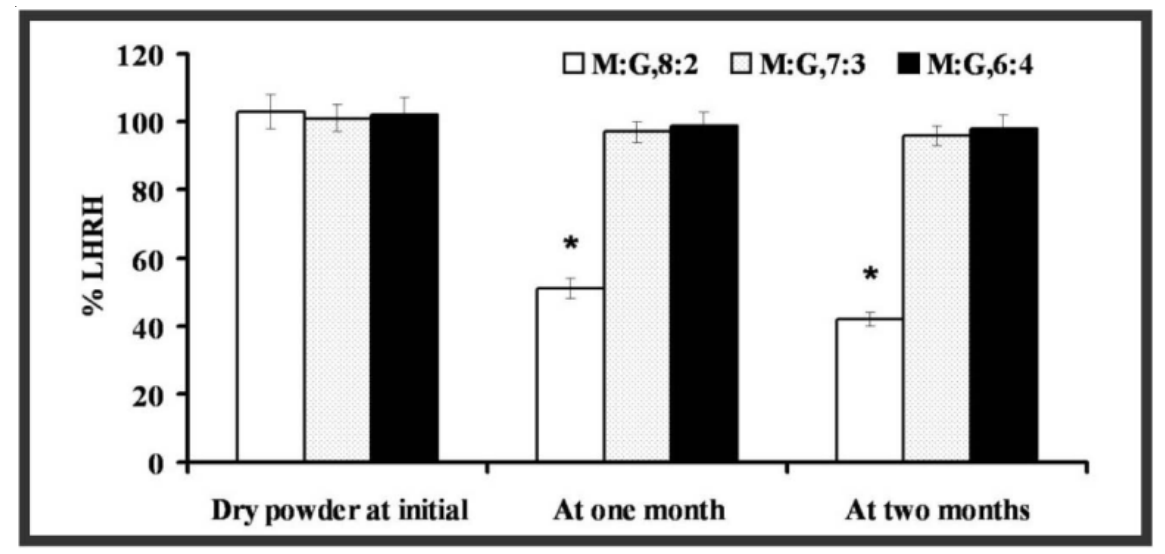

Figure 2. The percent content of LHRH formulations was analyzed by capillary electrophoresis of dry powders and dry powders after storage for one and two months. Each bar represents a mean $\pm \mathrm{SD}, \mathrm{n}=6$ and *p $<0.05$ compared to the initial value.

The in vitro time release of LHRH from dry powders was evaluated using dissolution apparatus. The dissolution of the LHRH formulations is shown in Figure 3. All LHRH formulations completely dissolved within 60 seconds. The LHRH formulation of M:G, 6:4 instantly dissolved in buffer at a faster rate than $M: G, 7: 3$ and $M: G, 8: 2$ formulations, respectively. The 6:4 (w/w) M:G formulation gave the highest amount of LHRH release, however, this amount was not significantly higher than the M:G, 8:2 formulation ( $p>0.05$ ). The release of M:G, 7:3, and $8: 2$ did not reach $100 \%$, which may be because of LHRH instability. It can be postulated that this type of formulation may not have a problem with LHRH release according to rapid dissolution.

The aggregation of LHRH in its solution form was monitored by the time-drive intensity of fluorescence.
Figure 4 shows time-drive intensity of LHRH solutions and reconstituted LHRH. The intensity of LHRH did not change over the first few weeks in both solution and powder form (one to two weeks). However, the intensity of the LHRH in solution increased rapidly after two weeks, especially for the M:G, 8:2 samples on day 21 and 28, as shown in A. On the other hand, the intensity of reconstituted LHRH dry powders containing M:G did not change after 35 days storage, as shown in B. It implied that the LHRH dry powder was stable from time drive intensity spectrum with no peak drifting. It is expected that LHRH is able to preserve its stability over two years and it is necessary to prove by following the longterm stability studies every six months over the period.

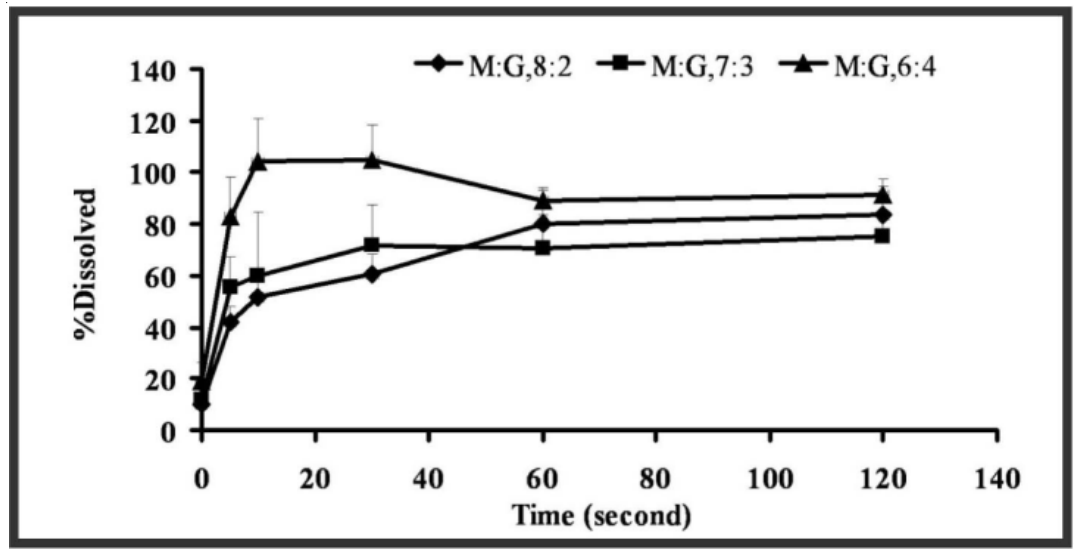

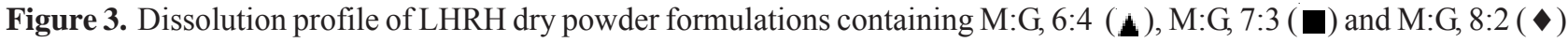
in diluted phosphate buffer $\mathrm{pH} 2.5$ (1:9 in water). Each point represents $\mathrm{a} \pm \mathrm{SD}, \mathrm{n}=6$. 


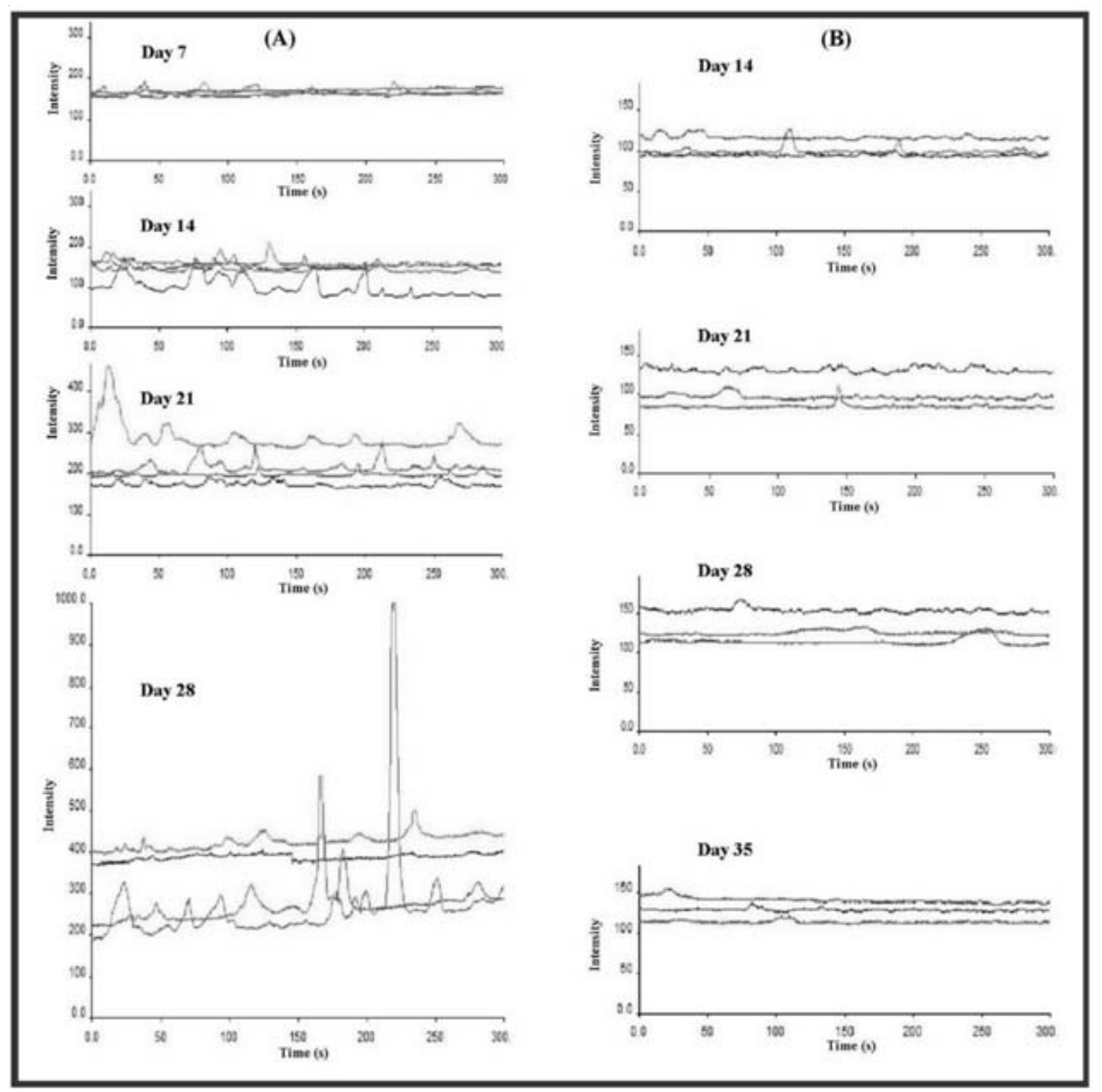

Figure 4. Time-drive intensity of LHRH solutions (A) and reconstituted LHRH (B) containing M:G, 8:2 (green), 7:3 (red), 6:4 (blue), and fresh LHRH (pink).

The particle size of LHRH formulations was determined by PCS. At initial, the LHRH in any formulation was in a solution with a size of $0.4 \mathrm{~nm}$. However, after six days, the PCS reported a size increase to $250 \mathrm{~nm}$ in case of pure LHRH solution whereas other three formulations (M:G, 8:2, 7:3 and 6:4) had a size of 264, 234, and $166 \mathrm{~nm}$ in respective order. It is likely that the reconstituted LHRH formulations had physical stability within five days at room temperature. However, at this size order, it is invisible. At 20 days, the size significantly increased in the range of 1600-6600 $\mathrm{nm}$ in all formulations. Particle sizes of LHRH solution and reconstituted LHRH formulations containing $10 \% \mathrm{M}$ to $\mathrm{G}$ with ratios of $8: 2,7: 3$ and $6: 4 \mathrm{w} / \mathrm{w}$ when dissolved in phosphate buffer pH 2.5 were 6620, 4843, 1773 and $1662 \mathrm{~nm}$, respectively. The results indicate that LHRH formulations were more stable than LHRH itself in phosphate buffer $\mathrm{pH} 2.5$. 
The deposition behavior of the LHRH dry powder formulations were studied by using TSI. Particle sizes less than five micro $\mathrm{m}$ are predicted to be able to enter the lower airways [31]. From the results obtained, it was found that the 6:4 ratio of M to G LHRH dry powder formulation with particle sizes less than 6.4 $\mu \mathrm{m}$ deposited on lower stage of the TSI for over $60 \%$, which is an ideal formulation for aerosolization. While the formulation containing M:G, 7:3 and 8:2 with sizes larger than $6.4 \mu \mathrm{m}$ LHRH deposited mainly on upper stage (deposition $=76.03 \%$ and $71.72 \%$, respectively) which is predicted that the LHRH is unlikely to travel to the lower airways. Therefore, these two formulations are not suitable for lung delivery. The plasma testosterone levels of male rats after intraperitoneal administration of LHRH suspensions are shown in Figure 5. After 28-days of intraperitoneal administration of LHRH suspensions, the plasma testosterone levels significantly decreased when compared to the control group $(15.0 \pm 1.0 \mathrm{ng} /$ $\mathrm{mL}, 15.0 \pm 1.0 \mathrm{ng} / \mathrm{mL}$ and $20.0 \pm 2.0 \mathrm{ng} / \mathrm{mL}$ for $\mathrm{LHRH}$ that contained M:G of; $6: 4,7: 3$ and $8: 2$, respectively when compared to the control of $35 \pm 2 \mathrm{ng} / \mathrm{mL}, \mathrm{p}<0.05$ ). These results are similar to those of Gharib et al. [32], and demonstrate that the LHRH retained its bioactivity after being transformed into a dry powder.

\section{Discussion}

LHRH for pulmonary formulation faces with the challenges of producing particles for deep-lung deposition without altering the native conformation of this peptide. Traditional techniques such as millings are not appropriate because it may deteriorate the activity during the production process. By spraying into deep freezing solution technique, a more advanced technique was employed to solve such a problem. The technique is very promising since it can preserve LHRH bioactivity. This technique is similar to supercritical fluid spray drying, but it is less expensive and run under atmospheric pressure. Therefore, it is more applicable in a small-scale production.

Pulmonary drug delivery is increasing as a route of drug administration for systemic activity peptide. The alveolar epithelium of the lung can be effectively targeted by delivering the peptide as aerosols with an aerodynamic size less than $5 \mu \mathrm{m}$. Peptides can pass alveolar membrane to enter the blood stream. This results in a high drug absorption that is achieved. LHRH dry powder formulation is an attraction method in that stability issues can be resolved. Further, dry powder offers an advantage with low susceptibility to hydrolysis and microbial growth. Peptides require an accurate dose, physico-chemical stability, and efficient

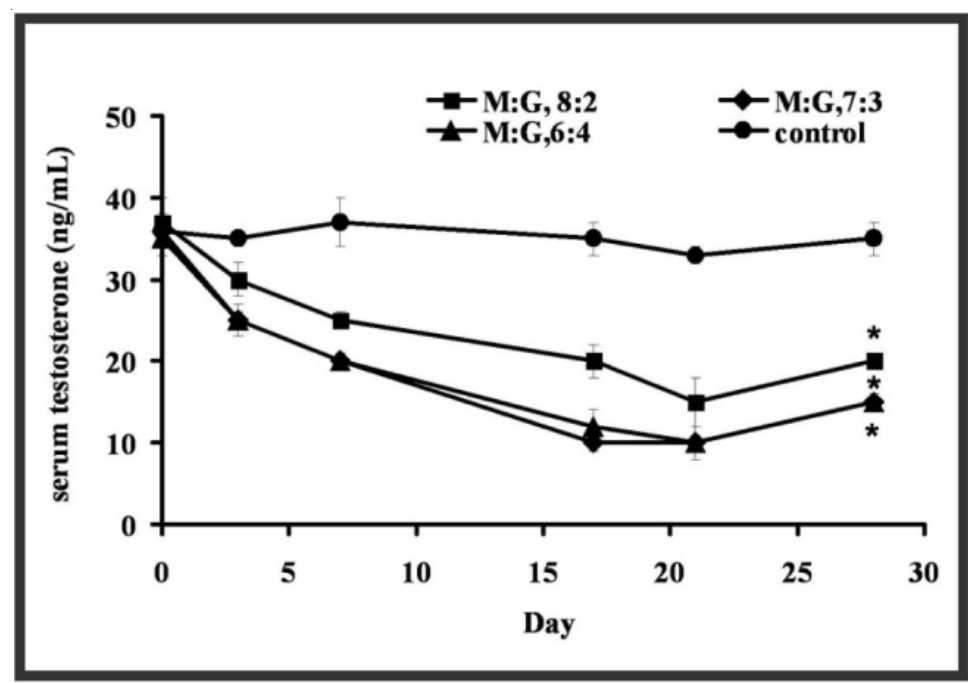

Figure 5. Changes of plasma testosterone levels after administration of LHRH suspensions containing 6:4 (w/w) M:G ( $(\boldsymbol{\Delta})$, 7:3 (w/w) M:G ( ), 8:2 (w/w) M:G (ם), and control $(\bullet)$. Each point represents mean \pm SD $(\mathrm{n}=6)$ and *p $<0.05$ compared to control value. 
deposition in the respiratory tract. In this case, formulation of LHRH containing 6:4 M:G was a promising formulation. In fact, it provided good aerosolization properties with high content of LHRH less than 6.4 micro $\mathrm{m}$, which is expected to reach the lower airways. The suitability of aerosol properties and the formulation can release the LHRH. The release profiles suggest that LHRH is rapid and influenced by the amount of mannitol incorporation. The initial burst release of LHRH appears to be promoted in this formulation.

It is observed that the aqueous solution of LHRH does not readily aggregation at $\mathrm{pH} 2.5$. However, at higher $\mathrm{pH}$ LHRH is unstable. The LHRH aggregation can be explained by the amino acids components of LHRH peptide. There are at least three amino acids components in the LHRH having a charge. These are Glu ( $\mathrm{pKa}=2.19$ at C-terminal and $\mathrm{pKa}=4.25$ at side chain), $\operatorname{Arg}(\mathrm{pKa}=12.48$ at side chain) and His ( $\mathrm{pKa}=6$ at side chain). The charge propensity in this case was positive depending on environmental $\mathrm{pH}$. At basic $\mathrm{pH}$, Glu shows negative charge. Considering that acidic $\mathrm{pH} 2.5$, LHRH have net charge of positive from Arg and His, and LHRH is likely to be more stable in acidic $\mathrm{pH}$ than the neutral $\mathrm{pH}$. At neutral $\mathrm{pH}$ 7, LHRH has both negative from Glu and positive charges from Arg that may cause intermolecular interaction and intra-molecular interactions. This is likely the major cause of aggregation and finally precipitation of LHRH. The prevention of peptide aggregation by adding glycine into LHRH solution might be able to solve or at least prevent the strong interaction between LHRH chains. As glycine has both a positive and negative charge in structure, the amino group of glycine can neutralize the free carboxyl of the glutamate at $\mathrm{C}$-terminal. The positive charge of Arg could be hindered by the carboxylic group of glycine. On the other hand, mannitol can insert among peptide chain and stabilize the LHRH peptide core structure. This results in a decrease of aggregation of the LHRH peptide, compared to free LHRH in phosphate buffer [33]. LHRH stabilization is successful since the bioactivity in animal model is preserved.

\section{Conclusion}

Three dry powder formulations of LHRH were successfully prepared by spray drying after incorporation of a mannitol and glycine carrier. These preparations were more stable than normal LHRH in solution form. In addition, the formulations comprising mannitol and glycine at a ratio of $6: 4$ and 7:3 were more stable than that with an 8:2 formulations. LHRH dry powder aerosols did not have altered properties, since all three formulations had bioactivity inducing reduced testosterone levels after injection into male rats.

\section{Acknowledgments}

We would like to thank the National Research University Project of Thailand's Office of the Higher Education Commission for financial support.

The authors have no conflict of interest to declare.

\section{References}

1. Tsai PS. Gonadotropin-releasing hormone in invertebrates: structure, function and evolution. Gen Comp Endocrinol. 2006; 148: 48-53.

2. Fernald RD, White RB. Gonadotropin-releasing hormone genes: phylogeny, structure and function. Front Neuroendocrinol. 1999; 20:224-40.

3. Millar RP. GnRHs and GnRH receptors. Anim Reprod Sci. 2005; 88:5-28.

4. Belsham DD, Lovejoy DA. Gonadotropin-releasing hormone: gene evolution, expression and regulation. Vitam Horm. 2006; 71:59-94.

5. Powell MF, Sanders LM, Rogerson A, Si V. Parenteral peptide formulations: Chemical and physical properties of native luteinizing hormone-releasing hormone (LHRH) and hydrophobic analogues in aqueous solution. Pharm Res. 1991; 10:1258-63.

6. Mezo G, Manea M. Luteinizing hormone-releasing hormone antagonists. Expert OpinTher Pat. 2009; 19: 1771-85.

7. Akaza H. Future prospects for luteinizing hormonereleasing hormone analogues in prostate cancer treatment. Pharmacology. 2010; 85:110-20.

8. Vercellini P, Somigliana E, Vigan P, Abbiati A, Barbara G, Crosignani PG. Endometriosis: current therapies and new pharmacological developments. Drugs. 2009; 69: 649-75.

9. Hackshaw A. Luteinizing hormone-releasing hormone (LHRH) agonists in the treatment of breast cancer. Expert Opin Pharmacother. 2009; 10:2633-9.

10. Helm VJ, Muller BW. Stability of gonadorelin and triptorelin in aqueous solution. Pharm Res. 1990; 12: 1253-6.

11. Pikal M. Freeze-drying of proteins, Part II. Formulation selection. Biopharmaceutics. 1990; 3:26-30.

12. Prestrelski S, Tedeschi N, Arakawa T, Carpenter J. 
Dehydration induced conformation transitions in proteins and their inhibition by stabilizers. Biophys J. 1993; 65: 661-71.

13. Allison SD, Chang B, Randolph TW, Carpenter J. Hydrogen bonding between sugar and protein is responsible for inhibition of dehydration-induced protein unfolding. Arch Biochem Biophys. 1999; 365 : 289-98.

14. Eriksson HJ, Hinrichs WL, van Veen B, Somsen GW, de Jong GJ, Frijlink HW. Investigations into the stabilization of drugs by sugar glasses: I. Tablets prepared from stabilized alkaline phosphatase. Int J Pharm. 2002;249:59-70.

15. Arakawa T, Timasheff SN. Stabilization of protein structure by sugars. Biochemistry. 1982;21:6536-44.

16. Arakawa T, Timasheff SN. Preferential interactions of proteins with salts in concentrated solutions. Biochemistry. 1983;21:6545-52.

17. Arakawa T, Timasheff SN. Mechanism of protein salting in and salting out by divalent cations: balance between hydration and salt binding. Biochemistry. 1984; 23: 5912-23.

18. Carpenter JP, Hand SC, Crowe LM, Crowe JH. Cryoprotection of phosphofructokinase with organic solutes: characterization of enhanced protection in the presence of divalent cations. Arch Biochem Biophys. 1986; 250:505-12.

19. Carpenter JF, Crowe JH. The mechanism of cryoprotection of proteins by solutes. Cryobiology. 1988;25:244-55.

20. Crowe JH, Crowe LM, Carpenter JF, Aurell Wistrom C. Stabilization of dry phospholipids bilayers and proteins by sugars. Biochem J. 1987; 242:1-10.

21. Wang W. Instability stabilization and formulation of liquid protein pharmaceutical. Int J Pharm. 1999; 185: 129-88.

22. Wang W. Lyophilization and development of solid protein pharmaceutical. Int J Pharm. 2000; 203:1-60

23. Liao YH, Brown MB, Martin GP. Investigation of the stabilization of freeze-dried lysozyme and the physical properties of the formulations. Eur J Pharm Biopharm. 2004; 58:15-24.

24. Nata a J, And anne B, Marc S, Michiel VS, Gerard WH, Geert JW, Daan JA, Wim J. Stable sugar-based protein formulations by supercritical fluid drying. Int $\mathrm{J}$ Pharm. 2008; 346:102-8.

25. Wearley LL. Recent progress in protein and peptide delivery by non-invasive routes. Crit Rev Ther Drug Carrier Syst. 1991; 8:1331-94.

26. Adjei AL, Gupta PK. Inhalation delivery of therapeutic peptides and proteins. New York:Marcel Dekker, 1997. p. $15-20$.

27. Srichana T, Suedee R, Srisudjai P. Application of spectrofluorometry for evaluation of dry powder inhalers in vitro. Pharmazie. 2003; 58:125-129.

28. Johnson KA. Preparation of peptide and protein powders for inhalation. Adv Drug Deliv Rev. 1997; 26: 3-15.

29. Schule H, Mechanisms and factors affecting intrapulmonary particle deposition: implications for efficient inhalation therapies. Pharm Sci Technol Today. 1998; 1:326-34.

30. Gerrit SZ, Wouter LJH, Anne HB, Henderik WF. The role of particle engineering in relation to formulation and de-agglomeration principle in the development of a dry powder formulation for inhalation of cetrorelix. Eur J Pharm Sci. 2004; 23:139-49.

31. Crowder TM, Rosati JA, Schroeter JD, Hickey AJ, Martonen TB. Fundamental effect of particle morphology on lung delivery: predictions of Stokes' law and the particular relevance to dry powder inhaler formulation and development. Pharm Res. 2002; 19: $239-45$.

32. Gharib SD, Wierman ME, Badger TM, Chin WW. Sex steroid hormone regulation of follicle-stimulating hormone subunit messenger ribonucleic acid (mRNA) levels in the rat. J Clin Invest. 1987; 80:294-9.

33. Nelson LM, Cox MM. Lehninger principle of biochemistry. New York; 2002. p. 118-9. 